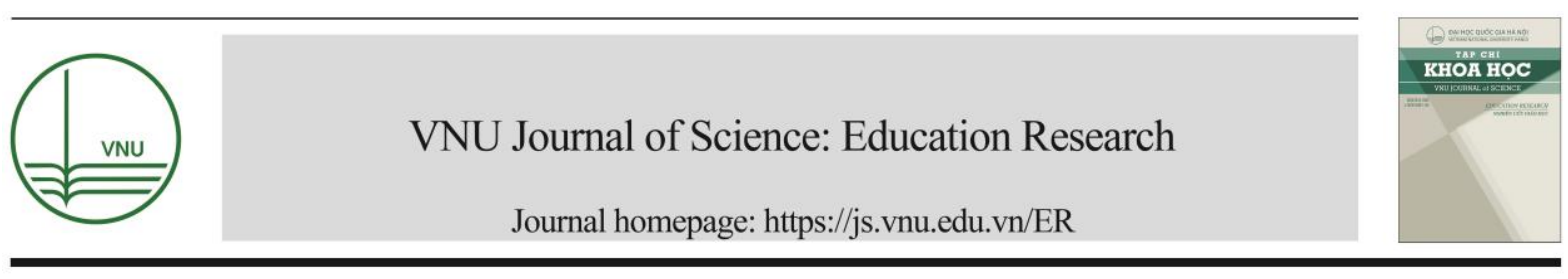

Original Article

\title{
Teachers' Awareness on Implementation of the Regulation on Assessing Elementary School Students Under Circular 22
}

\author{
Nguyen Cong Khanh ${ }^{1, *}$, Do Thi Huong ${ }^{2}$, Tran Thi $\mathrm{Ha}^{1}$ \\ ${ }^{1}$ Hanoi National University of Education, 136 Xuan Thuy, Cau Giay, Hanoi, Vietnam \\ ${ }^{2} V N U$ University of Education, Vietnam National University, Hanoi, \\ 144 Xиan Thuy, Cau Giay, Hanoi, Vietnam
}

Received 06 February 2020

Revised 09 March 2020; Accepted 16 March 2020

\begin{abstract}
This paper presents the results of teachers' awareness on the implementation of the regulation of assessing primary school students according to Circular 22. The survey sample consists of 813 teachers of some elementary schools in 6 provinces such as Lao Cai, Hanoi, Thua Thien Hue, Dak Lak, Tra Vinh and Ho Chi Minh City. The survey results showed that the majority of teachers have had a proper awareness of the purpose, principles, scientific bases and how to evaluate elementary school students according to the competency approach. At the same time, they also had very positive comments about the changes in behavior, their own perceptions and the implementation of teaching activities in the classroom towards developing capacity. However, a significant proportion of the surveyed teachers (about $40 \%$ of them) still had incorrect perceptions and beliefs and so far, they faced a number of difficulties. The results obtained from the survey are considered as a very useful document for management as well as educators to review the strengths and limitations in the process of implementation to devise strategies and remedies in the near future.
\end{abstract}

Keywords: Circular 22, regulations on assessment of primary school students, teachers, and perceptions.

\footnotetext{
${ }^{*}$ Corresponding author.

E-mail address: dothihuongctsv@gmail.com

https://doi.org/10.25073/2588-1159/vnuer.4349
} 


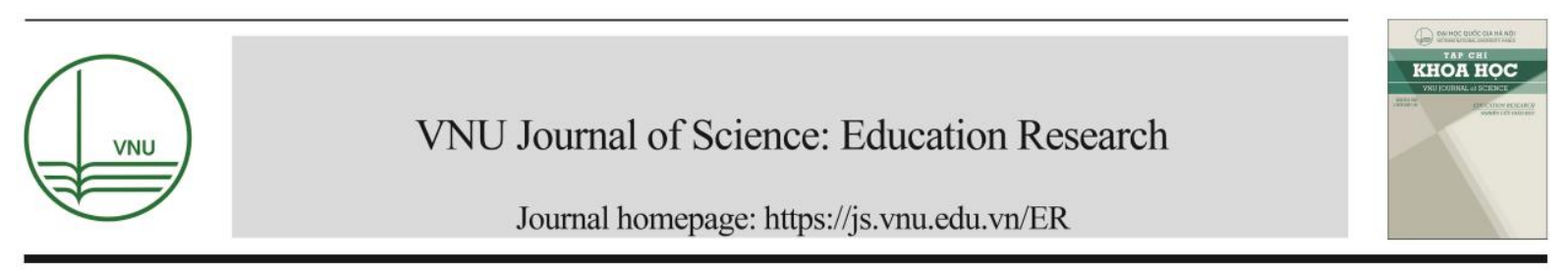

\title{
Nhận thức của giáo viên về thực hiện quy định đánh giá học sinh tiểu học theo Thông tư 22
}

\author{
Nguyễn Công Khanh ${ }^{1, *}$, Đỗ Thị Hướng ${ }^{2}$, Trần Thị Hà1 \\ ${ }^{1}$ Truòng Đại học Su pham Hà Nội, 136 Xuân Thủy, Cầu Giấy, Hà Nội, Việt Nam \\ ${ }^{2}$ Truoòng Đại học Giáo dục, Đại học Quốc gia Hà Nội, 144 Xuân Thủy, Cầu Giấy, Hà Nội, Việt Nam \\ Nhận ngày 06 tháng 02 năm 2020 \\ Chỉnh sửa ngày 09 tháng 3 năm 2020; Chấp nhận đăng ngày 16 tháng 3 năm 2020
}

\begin{abstract}
Tóm tắt: Bài báo trình bày kết quả nhận thức của giáo viên tiểu học về thực hiện quy định đánh giá học sinh tiểu học theo Thông tư 22 Đề tài tiến hành khảo sát trên 813 giáo viên của một số trường tiểu học thuộc 6 tỉnh (Lào Cai, Hà Nội, Thừa Thiên Huế, Đắc Lăk, Trà Vinh và thành phố Hồ Chí Minh). Kết quả nghiên cứu cho thấy, đại bộ phận giáo viên đã có những nhận thức đúng đắn về mục đích, nguyên tắc, cơ sở khoa học cũng như cách thức đánh giá học sinh tiểu học theo cách tiếp cận năng lực. Đồng thời họ cũng có những nhận xét rất tích cực về sự thay đổi trong hành vi, nhận thức của bản thân và cả việc thực hiện các hoạt động dạy học ở trên lớp theo hướng phát triển năng lực. Tuy nhiên vẫn tồn tại một bộ phận đáng kể (khoảng 40\%) giáo viên được khảo sát có những nhận thức và niềm tin chưa đúng. Những kết quả thu được từ nghiên cứu này giúp các cấp quản lí cũng như các nhà giáo dục nhìn nhận lại những điểm mạnh và hạn chế trong quá trình triển khai nhằm đưa ra những chiến lược, các biện pháp khắc phục trong thời gian tới.
\end{abstract}

Tư khóa: Thông tư 22, quy định đánh giá học sinh tiểu học, giáo viên tiểu học, nhận thức của giáo viên tiểu học.

\section{1. Đặt vấn đề}

Đánh giá từ lâu được coi là một trong những khâu quan trọng của hoạt động dạy và học, vì nó giúp các nhà giáo dục nắm được trình độ phát triển của học sinh cũng như giúp giáo viên nhìn nhận lại phương pháp, kĩ thuật dạy học, $\ldots$ của bản thân, từ đó không ngừng trau dồi, rèn luyện bản thân [1].

Thông tư 22 ra đời là sự tiếp nối thông tư 30 về quy định đánh giá học sinh tiểu học theo

\footnotetext{
* Tác giả liên hệ.

Địa chỉ email: dothihuongctsv@gmail.com

https://doi.org/10.25073/2588-1159/vnuer.4349
}

định hướng tiếp cận năng lực [2-4]. Về cơ bản, Thông tư 22 đã khắc phục được một số điểm còn hạn chế, thiết sót của Thông tư 30 và đã tạo ra được những chuyển biến tích cực trong đánh giá, nhận xét học sinh tiểu học nhằm đáp ứng yêu cầu đổi mới căn bản, toàn diện nền giáo dục phổ thông nói chung và giáo dục tiểu học nói riêng. Sau hơn 2 năm triển khai quy định đánh giá học sinh tiểu học theo Thông tư 22 , bên cạnh những thành tựu, đóng góp tích cực, thì vẫn còn tồn tại một số những trở ngại, khó khăn làm cản trở quá trình dạy và học [5].

Giáo viên là người trực tiếp thực hiện quy định đánh giá học sinh tiểu học theo Thông tư 22. Do đó, họ phải là người hiểu rõ mục đích, 
nội dung, nguyên tắc, cơ sở khoa học cũng như cách thức thực hiện các hoạt động đánh giá để đảm bảo thực hiện đầy đủ, có chất lượng hoạt động dạy và học theo tinh thần Thông tư 22 [6].

Nhận thức của giáo viên tiểu học về quy định đánh giá học sinh tiểu học theo Thông tư 22 là mức độ hiểu biết của họ về mục đích, nội dung, nguyên tắc, cơ sở khoa học, những chuyển biến tích cực của học sinh khi được đánh giá theo quy định này. Từ đó họ sẽ có thái độ và niềm tin tích cực trong triển khai, thực hiện quy định đánh giá này trên học sinh tiểu học nhằm đạt được những hiệu quả tối ưu nhất.

\section{Nội dung nghiên cứu}

\subsection{Nội dung, đối tượng và mẫu khảo sát}

\subsubsection{Nội dung khảo sát}

Đề tài tập trung làm sáng tỏ mức độ nhận thức của thông tư về các nội dung cơ bản trong quy định đánh giá học sinh tiểu học (như mục đích, nguyên tắc, nội dung, cách thức cũng như cơ sở khoa học để đưa ra quy định đánh giá này). Đồng thời cũng tìm hiểu thái độ, niềm tin của giáo viên khi thực hiện quy định đánh giá theo Thông tư 22 này; từ đó khảo sát về những khó khăn, bất cập mà giáo viên đang gặp phải; những kiến nghị về thay đổi, điều chỉnh để việc đánh giá học sinh tiểu học theo Thông tư 22 thật sự đem lại những hiệu quả thiết thực cho người học.

2.1.2. Mẫu khảo sát

Mẫu khảo sát bao gồm 813 giáo viên, gồm: Giáo viên chủ nhiệm, giáo viên phụ trách các môn chuyên biệt, như: Mĩ thuật, Âm nhạc, Tin học, Thể dục, ... tại các trường tiểu học tham gia khảo sát. Địa bàn khảo sát là 6 tỉnh đại diện cho 3 miền Bắc - Trung - Nam Việt Nam, gồm: Hà Nội, Lào Cai, Thừa Thiên Huế, Đắc Lắk, Trà Vinh và thành phố Hồ Chí Minh [5]. Mẫu khảo sát là những giáo viên trực tiếp tham gia vào công tác đánh giá học sinh tiểu học theo Thông tư 22 , không chỉ là giáo viên dạy những môn cơ bản (Toán, Tiếng Việt,...) mà còn có sự tham gia của các giáo viên chuyên biệt để tìm hiểu về mức độ nhận thức của họ về tinh thần đánh giá theo hướng đổi mới, cũng như những thuận lợi, khó khăn mà họ gặp phải trong quá trình triển khai dựa trên đặc thù của các môn học khác nhau.

\subsubsection{Phương pháp và công cụ khảo sát}

Phuoong pháp nghiên cưu: Trong bài báo này, chúng tôi sử dụng các phương pháp nghiên cứu sau:

- Phương pháp điều tra xã hội: Kết hợp cả định lượng (phiếu khảo sát) và định tính (toạ đàm).

- Phương pháp phân tích số liệu: Các phiếu khảo sát không trả lời đầy đủ, bị bỏ sót đều bị loại. Phần mềm SPSS 20.0 được dùng để xử lí số liệu thu được, trong đó có sử dụng thống kê mô tả để biết được thực trạng mức độ nhận thức theo các items; cronbach; alpha để kiểm tra độ tin cậy và hiệu lực của thang đo tổng nói chung và các item nói riêng; kiểm định $\mathrm{T}$-test, Anova để kiểm tra độ khác biệt giữa các biến.

Công cu khảo sát:

1) Phiếu khảo sát dành cho giáo viên gồm 7 nhóm câu hỏi:

Nhóm 1 (thang đo 1): Đánh giá mức độ thông hiểu của giáo viên về mục đích, nguyên tắc, cách thức đánh giá học sinh tiểu học theo Thông tư 22 gồm 9 items (câu hỏi 1) với thang bậc đánh giá gồm 5 mức độ (1. Rất không đồng ý/rất không đúng; 2. Cơ bản không đồng ý/không đúng; 3. Phân vân; 4. Đồng ý/đúng; 5. Rất đồng ý/rất đúng).

Nhóm 2 (thang đo 2): Đánh giá mức độ hiểu biết của giáo viên về cơ sở khoa học của quy định đánh giá học sinh tiểu học theo Thông tư 22 gồm 8 items (câu hỏi 2), cũng với thang bậc 5 mức độ như thang đo 1 .

Nhóm 3 (thang đo 3): Đánh giá thái độ, niềm tin của giáo viên về những thay đổi ở học sinh khi thực hiện quy định đánh giá học sinh tiểu học theo Thông tư 22 gồm 6 items (câu hỏi 3), với thang bậc đánh giá gồm 5 mức độ (1. Rất không đồng ý; 2. Cơ bản không đồng ý; 3. Phân vân; 4. Đồng ý; 5. Rất đồng ý).

Nhóm 4 (thang đo 4): Đánh giá cách thức thay đổi bản thân giáo viên khi thực hiện quy định đánh giá học sinh tiểu học theo Thông tư 22 gồm 10 items (câu hỏi 4), với thang bậc 
đánh giá gồm 5 mức độ như thang đo 3 , tập trung làm rõ có những thái độ niềm tin nào phù hợp và không phù hợp. Thang đánh giá sử dụng 5 mức độ như đã nêu ở trên.

Nhóm 5 (thang đo 5): Giáo viên đánh giá cách thức triển khai việc thực hiện quy định đánh giá học sinh tiểu học theo Thông tư 22 , gồm 9 items (câu hỏi 5), với thang bậc đánh giá gồm 5 mức độ (1. Chưa bao giờ; 2. Hiếm khi; 3. Thi thoảng; 4. Thường xuyên; 5. Rất thường xuyên).

Nhóm 6 (thang đo 6): Đánh giá những khó khăn giáo viên đã và đang gặp phải khi thực hiện đánh giá học sinh tiểu học theo Thông tư 22, gồm 15 items (câu hỏi 6), với thang bậc đánh giá gồm 5 mức độ (1. Không đúng/không gặp; 2. Hiếm khi đúng; 3. Thi thoảng đúng; 4. Thường xuyên đúng; 5 . Rất thường xuyên gặp phải/rất đúng).

Nhóm 7: Đánh giá những khó khăn, bất cập khi thực hiện đánh giá học sinh tiểu học theo Thông tư 222, gồm các câu hỏi mở (câu 7): Theo thầy/cô khi thực hiện Thông tư 22 tại trường mình giáo viên đã và đang có những khó khăn/ bất cập gì? Cần bổ sung điều chỉnh điều gì để sửa đồi quy định về đánh giá học sinh tiểu học giúp giáo viên đánh giá được các năng lực của học sinh tiểu học theo yêu cầu của chương trình giáo dục phổ thông mới? [5].

2) Toạ đàm: Tập trung vào những nội dung, như: Những khó khăn giáo viên gặp phải trong quá trình đánh giá học sinh; đề xuất của giáo viên tiểu học để thực hiện tốt nhiệm vụ đánh giá học sinh.

\section{2. Đánh giá tính chuẩn của công cu khảo sát}

\subsection{1. Độ tin cậy}

Để đánh giá độ tin cậy của bộ công cụ trong nghiên cứu này, đề tài dùng phương pháp đánh giá mức độ tương quan giữa các item trong cùng miền đo (internal consistency methods), sử dụng mô hình tương quan Alpha của Cronbach (Cronbach's Coefficient Alpha) [7].

Kết quả phân tích độ tin cậy của các tiểu thang đo trên bộ công cụ cho thấy tất cả các thang đo đều có hệ số tin cậy Cronbach alpha từ khá đến rất cao (từ 0.74 đến 0.94 ) [5].

Bảng 1. Độ tin cậy của các tiểu thang đo trên bộ công cụ khảo sát cán bộ quản lí

\begin{tabular}{ll}
\hline & Hệ số tin cậy Alpha \\
\cline { 2 - 2 } Các thang đo & $\begin{array}{l}\text { Mẫu giáo viên } \\
\mathrm{N}=813\end{array}$ \\
\hline Thang đo 1 (hiểu biết về mục đích, nguyên tắc, cách thức đánh giá của Thông tư 22) & 0.74 \\
Thang đo 2 (hiểu biết về cơ sở khoa học của Thông tư 22) & 0.77 \\
Thang đo 3 (niềm tin về sự thay đổi do Thông tư 22 đem lại với học sinh) & 0.78 \\
Thang đo 4 (niềm tin về sự thay đổi do Thông tư 22 đem lại với giáo viên) & 0.82 \\
Thang đo 5 (cách thức giáo viên trong trường đánh giá học sinh theo Thông tư 22) & 0.82 \\
Thang đo 6 (khó khăn của giáo viên khi thay đồi cách đánh giá học sinh theo Thông tư 22) & 0.92 \\
\hline Toàn thang đo & 0.94 \\
\hline
\end{tabular}

\subsection{2. Đánh giá độ giá trị}

Để đánh giá độ hiệu lực cấu trúc, đề tài dùng phương pháp phân tích yếu tố. Kết quả phân tích yếu tố cho thấy từng thang đo đều có độ hiệu lực cấu trúc khá tốt. Các item trong từng thang đo có tính đồng hướng (hệ số chứa factor loading từ 0.625 đến 0.834 ) - tức là cùng đo một thành tố. Điểm số các thang đo có tương quan thuận khá chặt (từ 0.401 đển 0.769 ) [5].
Điều này phù hợp với thực tế và phản ánh đúng các quan hệ mong muốn, được giả thiết trong cấu trúc của phép đo.

\subsection{Kết quả khảo sát thực trạng}

2.3.1. Thực trạng nhận thức của giáo viên

2.3.1.1. Nhận thức của giáo viên về mục đích, nguyên tắc, cách thức đánh giá học sinh tiểu học trong Thông tư 22. 
Giáo viên hiểu biết như thế nào về mục đích, nguyên tắc, cách thức đánh giá học sinh tiểu học theo Thông tư 22? Kết quả tại Bảng 2 cho thấy, giáo viên trả lời Đồng ý trên các item số: $1,2,3$, thể hiện sự hiểu đúng mục đích của Quy định đánh giá học sinh tiểu học theo Thông tư 22. Số giáo viên trả lời đồng ý chiếm tỷ lệ từ $64,3 \%$ dến $86,4 \%$. Như vậy, vẫn còn một bộ phận đáng kể giáo viên (từ $14 \%$ đến $36 \%$ ) chưa thật sự hiểu rõ mục đích đánh giá của Thông tư 22. Kết quả trả lời đồng ý trên các item số: 7,8 , 9 thể hiện sự hiểu đúng cách thức, nguyên tắc đánh giá học sinh tiểu học của Thông tư 22. Số giáo viên trả lời đồng ý chiếm tỷ lệ từ $75,2 \%$ đến $84,5 \%$. Như vậy vẫn còn từ $15-25 \%$ số giáo viên được khảo sát chưa hiểu rõ cách thức, nguyên tắc đánh giá học sinh tiểu học theo Thông tư 22 . Kết quả khảo sát này cho thấy cần thiết phải tuyên truyền, tập huấn kỹ hơn, sâu hơn để giáo viên hiểu rõ về Thông tư 22 .

Có khoảng 3/4 số giáo viên được hỏi hiểu và phân biệt được bản chất của đánh giá thường xuyên và đánh giá tổng kết nhằm những mục đích khác nhau khi trả lời item số 3: "Mục đích chính của đánh giá tổng kết nhằm phân loại, xếp hạng học sinh, ngược lại mục đích chính của đánh giá thường xuyên là thúc đẩy, phát triển học tập" - có 74\% giáo viên được hỏi đồng ý với nhận định này.

Kết quả khảo sát giáo viên cho thấy có một bộ phận đáng kể giáo viên được hỏi cho rằng đánh giá bằng điểm số mới chính xác, đánh giá bằng nhận xét khó chính xác. Cụ thể, có 44,4\% giáo viên được khảo sát đồng ý với ý kiến (item số 4) cho rằng "việc đánh giá học sinh bằng điểm số thì mới chính xác".

Bảng 2. Nhận thức (sự thông hiểu) của giáo viên về Thông tư 22

\begin{tabular}{|c|c|c|c|c|c|c|}
\hline \multirow{2}{*}{$\mathrm{Stt}$} & \multirow{2}{*}{$\begin{array}{l}\text { Các ý kiến/nhận định về nhận thức mục đích, cách thức thực hiện } \\
\text { đánh giá học sinh tiểu học theo Thông tư } 22\end{array}$} & \multicolumn{5}{|c|}{ Mức độ \% } \\
\hline & & 1 & 2 & 3 & 4 & 5 \\
\hline 1 & $\begin{array}{l}\text { Mục đích chính của đánh giá thường xuyên không nhằm phân } \\
\text { loại, xếp hạng học sinh mà là thúc đây, phát triển hoạt động } \\
\text { học tập. }\end{array}$ & 2,1 & 5,9 & 5,7 & 65,1 & 21,3 \\
\hline 2 & $\begin{array}{l}\text { Đánh giá thường xuyên chủ yếu nhằm phản hồi, phát hiện lỗi để } \\
\text { kịp thời điều chỉnh hoạt động dạy và học thì sử dụng nhận xét } \\
\text { tích cực tốt hơn là cho điểm số. }\end{array}$ & 3,4 & 13,2 & 19,1 & 50,4 & 13,9 \\
\hline 3 & $\begin{array}{l}\text { Mục đích chính của đánh giá tổng kết nhằm phân loại, xếp hạng } \\
\text { học sinh, ngược lại mục đích chính của đánh giá thường xuyên là } \\
\text { thúc đầy, phát triền học tập. }\end{array}$ & 4,2 & 6,4 & 15,4 & 58,4 & 15,6 \\
\hline 4 & $\begin{array}{l}\text { Nhiều giáo viên luôn cho rằng, việc đánh giá học sinh bằng điểm } \\
\text { số thì mới chính xác, suy nghĩ của bạn cũng giông như họ. }\end{array}$ & 7,1 & 28,4 & 20,0 & 32,0 & 12,4 \\
\hline 5 & $\begin{array}{l}\text { Nhiều phụ huynh luôn tin rằng, việc đánh giá học sinh chỉ thông } \\
\text { qua điểm số thì mới chính xác, bạn cũng tin giống như họ. }\end{array}$ & 9,8 & 36,2 & 13,0 & 31,0 & 10,0 \\
\hline 6 & $\begin{array}{l}\text { Đánh giá thường xuyên học sinh bằng nhận xét, không chấm } \\
\text { điểm, học sinh sẽ lười học hơn, bạn cũng có suy nghĩ giống họ. }\end{array}$ & 8,4 & 26,0 & 12,7 & 40,5 & 12,5 \\
\hline 7 & $\begin{array}{l}\text { Thông tư } 22 \text { giúp giáo viên thay đổi nhận thức: Coi trọng đánh } \\
\text { giá quá trình để phát triển người học. }\end{array}$ & 1,2 & 3,8 & 12,8 & 62,4 & 19,8 \\
\hline 8 & $\begin{array}{l}\text { Đánh giá thường xuyên bằng nhận xét làm giảm áp lực điểm số } \\
\text { và tránh sự mặc cảm tự ti ở học sinh tiểu học. }\end{array}$ & 1,7 & 8,5 & 14,6 & 52,4 & 22,8 \\
\hline 9 & $\begin{array}{l}\text { Khi học sinh thường xuyên được nhận xét, đánh giá lẫn nhau sẽ } \\
\text { giúp các em tự phát hiện ra lồi sai của nhau mà không sợ làm các } \\
\text { em bị thương tồn. }\end{array}$ & 0,6 & 6,5 & 8,4 & 61,1 & 23,4 \\
\hline
\end{tabular}

(*Mức độ: $1=$ Rất không đồng ý/rất không đúng; 2 = Cơ bản không đồng ý/không đúng; 3 = Phân vân; 4 = Đồng ý/đúng; 5 = Rất đồng ý/ rất đúng) 
Có $41 \%$ giáo viên đồng ý với ý kiến của phụ huynh (item số 5) cho rằng "việc đánh giá học sinh chỉ thông qua điểm số thì mới chính xác". Có tới $53 \%$ giáo viên đồng ý với ý kiến (item số 6) cho rằng "đánh giá thường xuyên học sinh bằng nhận xét, không chấm điểm, học sinh sẽ lười học hơn". Đây là những suy nghĩ, nhận định cảm tính, không có cơ sở khoa học, nhưng vẫn có gần $1 / 2$ số giáo viên được hỏi tin vào nhận định này [6]. Điều này rất đáng quan ngại khi giáo viên chưa thật sự thông hiểu một cách rõ ràng đúng bản chất của Thông tư 22 và chính những suy nghĩ, niềm tin sai lệch này đang cản trở sự thay đổi nhận thức ở giáo viên khi họ thực hiện quy định đánh giá học sinh theo Thông tư 22 .

2.3.1.2. Nhận thức của giáo viên về cơ sở khoa học (tâm lý học, giáo dục học và khoa học đo lường đánh giá giáo dục) trong Thông tư 22

Kết quả nghiên cứu cho thấy giáo viên được khảo sát có sự hiểu biết nhất định, khá phù hợp về cơ sở tâm lý học, giáo dục học và khoa học đo lường đánh giá giáo dục làm cơ sở nền tảng cho Quy định đánh giá học sinh tiểu học theo Thông tư 22. Kết quả trả lời trên các item số: $1,2,3,4$, thể hiện sự đồng ý chiếm tỷ lệ khá cao (từ 78,7\% đến 93,2\%). Đây là những item phản ánh cơ sở khoa học (đã được các nghiên cứu nước ngoài và trong nước thừa nhận) chỉ ra đánh giá học sinh tiểu học bằng nhận xét tích cực có lợi cho sự phát triển nhân cách học sinh tiểu học. Tuy nhiên, do giáo viên đã quen đánh giá học sinh bằng điểm số, chưa hoặc ít khi đánh giá thường xuyên bằng những nhận xét tích cực, không cần cho điểm, nên chỉ có gần $60 \%$ giáo viên được khảo sát đồng ý rằng: Đánh giá thường xuyên không dùng điểm số mà sử dụng những nhận xét tích cực sẽ có lợi hơn cho sự phát triển hoạt động học tập $(57,8 \%$ giáo viên đồng ý, $25,2 \%$ giáo viên phân vân và $16,9 \%$ không đồng ý với ý kiến này).

Đa số giáo viên được khảo sát có niềm tin tích cực vào những thay đổi và lợi ích của Thông tư 22 , đã và đang nỗ lực thực hiện quy định này để tạo ra những thay đổi tích cực trong dạy học và đánh giá học sinh. Có $74,3 \%$ giáo viên tin rằng (item số 6 ): "Những lời nhận xét tiêu cực của giáo viên với học sinh tiểu học có thể xói mòn niềm tin tích cực, làm mất hứng thú học đường, làm sai lệch sự phát triển nhân cách". Có 85,5\% giáo viên cho rằng (item số 7): "Đánh giá thường xuyên bằng những nhận xét tích cực "có thể chạm đến trái tim học sinh" sẽ tạo dựng niềm tin, nuôi dưỡng hứng thú học đường". Có $78,4 \%$ giáo viên cho rằng (item số 8): "Tôi tin rằng mình đã thực hiện có hiệu quả việc dạy học và đánh giá theo tinh thần đổi mới của thông tư 22 để thúc đẩy, phát triển học tập của học sinh tiểu học". Điều này cho thấy việc tập huấn chuyên môn để giáo viên hiểu tầm quan trọng của những lời nhận xét trực tiếp, biết các kỹ thuật đưa ra những lời nhận xét tích cực, phù hợp với ngữ cảnh tình huống học tập cần thiết phải được tiếp tục triển khai ở các trường tiểu học (Bảng 3 ).

Bảng 3. Hiểu biết của giáo viên về cơ sở khoa học Thông tư 22

\begin{tabular}{|c|c|c|c|c|c|c|}
\hline \multirow{2}{*}{ Stt } & \multirow{2}{*}{$\begin{array}{l}\text { Các ý kiến/nhận định về cơ sở khoa học khi thực hiện đánh giá } \\
\text { học sinh tiểu học theo Thông tur } 22\end{array}$} & \multicolumn{5}{|c|}{ Mức độ \% } \\
\hline & & 1 & 2 & 3 & 4 & 5 \\
\hline 1 & $\begin{array}{l}\text { Suy nghĩ và cảm nhận của học sinh tiểu học chịu ảnh hưởng } \\
\text { rất nhiều từ những lời nhận xét trực tiếp của giáo viên. }\end{array}$ & 3,0 & 10,6 & 7,7 & 60,4 & 18,3 \\
\hline 2 & $\begin{array}{l}\text { Học sinh tiểu học xây dựng niềm tin, hứng thú học đường trên } \\
\text { cở sở những lời nhận xét trực tiếp của giáo viên trong những } \\
\text { tình huống học tập. }\end{array}$ & 0,6 & 4,2 & 8,5 & 69,0 & 17,7 \\
\hline 3 & $\begin{array}{l}\text { Những lời nhận xét trực tiếp, tích cực của giáo viên với học sinh } \\
\text { tiểu học có sức mạnh tạo dựng niềm tin, truyền cảm hứng } \\
\text { học đường. }\end{array}$ & 1,0 & 1,2 & 4,6 & 62,0 & 31,2 \\
\hline 4 & $\begin{array}{l}\text { Mọi học sinh tiểu học đều có thể thành công học đường, nếu } \\
\text { giáo viên luôn tin và gieo ý nghĩ, niềm tin ẩy mỗi ngày bằng } \\
\text { những lời nhận xét tích cực trực tiếp với từng em. }\end{array}$ & 1,1 & 4,1 & 12,9 & 57,9 & 24,0 \\
\hline
\end{tabular}




\begin{tabular}{|c|c|c|c|c|c|c|}
\hline 5 & $\begin{array}{l}\text { Đánh giá thường xuyên không dùng điểm số mà sử dụng } \\
\text { những nhận xét tích cực sẽ có lợi hơn cho sự phát triển hoạt } \\
\text { động học tập. }\end{array}$ & 1,8 & 15,1 & 25,2 & 44,3 & 13,5 \\
\hline 6 & $\begin{array}{l}\text { Những lời nhận xét tiêu cực của giáo viên với học sinh tiểu } \\
\text { học có thể sói mòn niềm tin tích cực, làm mất hứng thú học } \\
\text { đường, làm sai lệch sự phát triển nhân cách. }\end{array}$ & 4,4 & 11,3 & 10,0 & 53,9 & 20,4 \\
\hline 7 & $\begin{array}{l}\text { Đánh giá thường xuyên bằng những nhận xét tích cực "có thể } \\
\text { chạm đến trái tim học sinh" sẽ tạo dựng niềm tin, nuôi dưỡng } \\
\text { hứng thú học đường. }\end{array}$ & 1,4 & 3,9 & 9,2 & 58,8 & 26,7 \\
\hline 8 & $\begin{array}{l}\text { Tôi tin rằng mình đã thực hiện có hiệu quả việc đánh giá học } \\
\text { sinh theo tinh thần đổi mới của Thông tư } 22 \text { để thúc đẩy, phát } \\
\text { triển học tập của học sinh tiểu học. }\end{array}$ & 0,2 & 3,1 & 18,2 & 62,7 & 15,7 \\
\hline
\end{tabular}

(*Mức độ: $1=$ Rất không đồng ý/rất không đúng; 2 = Cơ bản không đồng ý/không đúng; 3 = Phân vân; 4 = Đồng ý/đúng; 5 = Rất đồng ý/rất đúng).

2.3.1.3. Nhận thức của giáo viên về những thay đổi của bản thân khi thực hiện đánh giá học sinh tiểu học theo Thông tư 22

Đa số giáo viên được khảo sát có những nhận định tích cực về những thay đổi ở bản thân họ, khi thực hiện quy định đánh giá học sinh tiểu học theo Thông tư 22. Kết quả trả lời của giáo viên trên các item số: $1,2,3,4,5,6$, thể hiện sự đồng ý chiếm tỷ lệ khá cao (từ 87,4\% đến 94,3\%). Đây là những nhận định của chính giáo viên - những người đang trực tiếp thực hiện quy định đánh giá học sinh tiểu học theo Thông tư 22. Điều này khẳng định Thông tư 22 đang tạo ra những thay đổi tích cực ở giáo viên, không thể phủ nhận, dù vẫn còn một bộ phận đáng kể giáo viên có những suy nghĩ, nhận định cảm tính, nghi ngờ cách thức đánh giá học sinh tiểu học quy định trong Tông tư 22 (Bảng 4).

Bảng 4. Đánh giá những thay đổi ở giáo viên, khi thực hiện Thông tư 22

\begin{tabular}{|c|c|c|c|c|c|c|}
\hline \multirow{2}{*}{ Stt } & \multirow{2}{*}{$\begin{array}{l}\text { Triển khai thực hiện đánh giá theo Thông tư } 22 \text { đã tác động } \\
\text { đến giáo viên }\end{array}$} & \multicolumn{5}{|c|}{ Mức độ \% } \\
\hline & & 1 & 2 & 3 & 4 & 5 \\
\hline 1 & $\begin{array}{l}\text { Tôi đã thay đổi nhâan thức về mục đích đánh giá học sinh: } \\
\text { đánh giá để phát triền học tập. }\end{array}$ & 0,6 & 1,1 & 7,9 & 71,8 & 18,6 \\
\hline 2 & $\begin{array}{l}\text { Tôi đã thay đổi nhận thức về yêu cầu/nguyên tắc đánh giá học } \\
\text { sinh tiểu học. }\end{array}$ & 0,1 & 1,5 & 10,9 & 74,4 & 13,0 \\
\hline 3 & $\begin{array}{l}\text { Tôi đã thay đổi thói quen đánh giá thường xuyên bằng điểm } \\
\text { số sang đánh giá thường xuyên bằng nhận xét tích cực. }\end{array}$ & 0,2 & 2,1 & 5,3 & 72,1 & 20,3 \\
\hline 4 & $\begin{array}{l}\text { Tôi sử dụng sổ cá nhân ghi chép thông tin về sự tiến bộ của } \\
\text { mỗi học sinh để hố trợ kịp thời. }\end{array}$ & 0,5 & 3,9 & 6,4 & 74,4 & 14,8 \\
\hline 5 & $\begin{array}{l}\text { Tôi đã phối hợp chă̆t chẽ với cha mẹ để có đủ thông tin khi } \\
\text { đánh giá phẩm chât, năng lực của học sinh. }\end{array}$ & 0,2 & 2,5 & 7,5 & 68,0 & 21,8 \\
\hline 6 & $\begin{array}{l}\text { Tôi đã thay đổi phương pháp, cách thức tổ chức dạy học để } \\
\text { phát triển toàn diện các năng lực, phẩm chất nhân cách của } \\
\text { từng hoc sinh. }\end{array}$ & 0 & 1,2 & 4,4 & 72,4 & 21,9 \\
\hline
\end{tabular}

(*Mức độ: 1. Hoàn toàn không đồng ý; 2. Không đồng ý; 3. Phân vân; 4. Đồng ý; 5. Rất đồng ý).

2.3.2. Thực trạng thực hiện các hoạt động đánh giá học sinh tiểu học theo Thông tư 22 của giáo viên tiểu học

Có $93 \%$ giáo viên được khảo sát cho rằng họ thường xuyên: "Sử dụng nhận xét tích cực với học sinh, không sử dụng điểm số trong đánh giá thường xuyên" (item số 2 ). Có từ $74,4 \%$ đến $75,9 \%$ giáo viên được khảo sát cho rằng họ thường xuyên thực hiện các hoạt động: sử dụng sổ cá nhân, hướng dẫn học sinh tự đánh giá, sử 
dụng trò chơi trong quá trình đánh giá, viết nhận xét vào phiếu, vở học sinh (item số $1,3,4$, 5. Có $80,6 \%$ giáo viên được khảo sát cho rằng họ thường xuyên: "Sử dụng những lời nhận xét với cảm xúc tích cực, có thể "chạm đến trái tim trẻ" trong các bài học/tình huống học tập trên lớp học". Có $66,2 \%$ giáo viên được khảo sát cho rằng họ có thực hiện thường xuyên hoạt động sau: "sử dụng các sự kiện, hiện tượng, tình huống trong cuộc sống, làm thành các câu hỏi, bài tập để đánh giá năng lực vận dụng của học sinh" (Bảng 5).

Kết quả khảo sát dựa trên các câu hỏi mở cho thấy bước đầu có sự thay đổi trong nhận thức của giáo viên rằng đánh giá thường xuyên bằng lời nhận xét trực tiếp, với cảm xúc tích cực có ảnh hưởng chi phối thúc đẩy phát triển học tập, phát triển nhân cách học sinh tiểu học. Tuy nhiên, các chuyên gia giáo dục, các cấp quản lý giáo dục vẫn cần chú ý nhiều hơn đến hoạt động cung cấp những tri thức liên quan đến cơ sở khoa học để giáo viên và phụ huynh hiểu lợi ích của đánh giá bằng nhận xét đối với sự phát triển nhân cách học sinh, từ đó thay đổi nhận thức của họ. Cần tập huấn, hướng dẫn kỹ hơn các kỹ thuật nhận xét bằng lời để tăng cường hiệu quả thực hiện quy định đánh giá bằng nhận xét trong Thông tư 22 .

Bảng 5. Giáo viên thực hiện các hoạt động đánh giá học sinh theo Thông tư 22

\begin{tabular}{|c|c|c|c|c|c|c|}
\hline \multirow{2}{*}{ Stt } & \multirow{2}{*}{ Thực hiện các hoạt động đánh giá theo Thông tư 22} & \multicolumn{5}{|c|}{ Mức độ thực hiện \% } \\
\hline & & 1 & 2 & 3 & 4 & 5 \\
\hline 1 & $\begin{array}{l}\text { Quan sát, theo dõi, ghi chép kết quả thực hiện nhiệm vụ của } \\
\text { từng học sinh vào sồ cá nhân. }\end{array}$ & 0,5 & 3,1 & 21,8 & 61,6 & 12,9 \\
\hline 2 & $\begin{array}{l}\text { Sử dụng nhận xét tích cực với học sinh, không sử dụng điểm } \\
\text { số trong đánh giá thường xuyên. }\end{array}$ & 0,2 & 2,0 & 4,8 & 65,7 & 27,3 \\
\hline 3 & $\begin{array}{l}\text { Viết lời nhận xét vào phiếu, vở của học sinh về những kết } \\
\text { quả đã làm được. }\end{array}$ & 0,1 & 2,1 & 9,7 & 61,6 & 26,3 \\
\hline 4 & $\begin{array}{l}\text { Tố chức cho học sinh học tự đánh giá và đánh giá lẫn nhau } \\
\text { theo nhóm nhỏ. }\end{array}$ & 0,4 & 2,2 & 19,3 & 61,4 & 16,7 \\
\hline 5 & $\begin{array}{l}\text { Dùng các trò chơi ngắn (1-3 phút) để tạo sự thân thiện, thoái } \\
\text { mái trong lớp học. }\end{array}$ & 0,2 & 1,2 & 21,9 & 58,1 & 18,6 \\
\hline 6 & $\begin{array}{l}\text { Sử dụng những lời nhận xét với cảm xúc tích cực, có thể } \\
\text { "chạm đến trái tim học sinh" trong các bài học/tình huống } \\
\text { học tập trên lớp học. }\end{array}$ & 1,1 & 2,0 & 16,4 & 63,5 & 17,1 \\
\hline 7 & $\begin{array}{l}\text { Sử dụng các sự kiện, hiện tượng, tình huống trong cuộc } \\
\text { sống, làm thành các câu hỏi, bài tập để đánh giá năng lực } \\
\text { vận dụng của học sinh. }\end{array}$ & 0,4 & 3,2 & 30,3 & 53,4 & 12,8 \\
\hline 8 & $\begin{array}{l}\text { Đưa ra các câu hỏi, bài tập nhằm đánh giá năng lực vận } \\
\text { dụng của học sinh. }\end{array}$ & 0,2 & 1,1 & 13,0 & 70,2 & 15,4 \\
\hline 9 & $\begin{array}{l}\text { Tồ chức cho học sinh tự đánh giá và đánh giá lẫn nhau trong } \\
\text { các giờ học. }\end{array}$ & 0,4 & 2,7 & 15,0 & 65,3 & 16,6 \\
\hline 10 & $\begin{array}{l}\text { Sử dụng các thang đo để đánh giá phẩm chất và năng lực } \\
\text { chung của học sinh. }\end{array}$ & 3,4 & 7,0 & 27,1 & 53,9 & 8,6 \\
\hline
\end{tabular}

(*Mức độ: $1=$ Chưa bao giờ; $2=$ Hiếm khi; $3=$ Thi thoảng; $4=$ Thường xuyên; $5=$ Rất thường xuyên)

2.3.3. Những khó khăn của giáo viên khi thực hiện quy định đánh giá học sinh tiểu học theo Thông tư 22

Kết quả tại Bảng 6 cho thấy, có $19,4 \%$ đến $24,3 \%$ giáo viên được khảo sát cho rằng họ thường xuyên gặp các khó khăn (item số 13, 12, $9,3)$ : Đưa ra nhận xét bằng lời tích cực; đánh giá hiệu quả các hoạt động trải nghiệm thực tế của học sinh; thiết kế ma trận đề và viết các câu hỏi đánh giá năng lực vận dụng và vận dụng sáng tạo của học sinh (mức 3 và 4 ); viết những lời nhận xét phù hợp với từng học sinh. Kết quả giáo viên tự đánh giá trên 14 nhóm khó khăn trong thực hiện đánh giá học sinh tiểu học theo 
Thông tư 22, được liệt kê trong bảng hỏi, tỉ lệ giáo viên trả lời ở mức 3 (phân vân - không khẳng định được mình có thực sự khó khăn hay không) khá cao (từ $30,6 \%$ đến $47,8 \%$ ), chỉ có từ $32,6 \%$ đến $55 \%$ giáo viên được khảo sát tự tin khẳng định mình không thực sự gặp khó khăn khi thực hiện đánh giá học sinh theo Thông tư 22.

Phân tích kết quả các cuộc trao đổi, tọa đàm mở ngay sau khi giáo viên trả lời phiếu khảo sát cho thấy, giáo viên vẫn đang gặp nhiều khó khăn (hơn những gì họ đã trả lời trong phiếu khảo sát) khi đánh giá học sinh theo các yêu cầu của Thông tư 22. Chẳng hạn, khi xem xét các bài kiểm tra cuối kì I, II năm học 2017-2018 và cuối kì I năm học 2018-2019 ở các môn học có bài kiểm tra viết, $70 \%$ các câu hỏi kiềm tra thuộc mức 1-2 (mức biết và hiểu), khoảng 20\% câu hỏi kiểm tra ở mức 3 (vận dụng) và khoảng 10\% mức 4 (vận dụng linh hoạt sáng tạo). Các câu hỏi ở mức 3 thực chất mới ở ranh giới giữa mức 2 và 3 . Câu hỏi ở mức 4 phần nhiều vẫn đang dừng lại ở mức 3 hoặc có thiên hướng sử dụng những câu hỏi khó, nâng cao trong các sách tham khảo, vẫn chưa chú trọng đến các câu hỏi vận dụng nội dung đã học vào lí giải sự kiện, hiện tượng, giải quyết các tình huống trong đời sống thực của xã hội. Với những câu hỏi mở, như: Giáo viên muốn điều chỉnh, bổ sung những gì trong Thông tư 22 khi áp dụng chương trình giáo dục phổ thông mới,... có trên $50 \%$ giáo viên mong muốn Bộ Giáo dục và Đào tạo cho phép kết hợp đánh giá bằng nhận xét và điểm số trong đánh giá thường xuyên, thay đổi các mức khen thưởng (có thêm mức giỏi trước xuất sắc). Một thực tế giáo viên vẫn có xu hướng chạy theo thành tích, muốn có nhiều học sinh được xếp loại xuất sắc vào cuối năm dù họ biết rõ những em này chưa thực sự xuất sắc. giáo viên đưa ra nhiều lý do, như: sức ép của cha mẹ học sinh, tỷ lệ học sinh xuất sắc ở các trường khác cao (khoảng $40 \%$ và nhiều trường trên $40 \%$ ) dù giáo viên và cán bộ quản lí của trường đều biết tỷ lệ học sinh xuất sắc thực tế thấp hơn nhiều. Nhóm nghiên cứu cũng nhận thấy, có sự mâu thuẫn khi những trường được thừa nhận có chất lượng tốt (ở nội thành các thành phố, thị xã) có tỷ lệ học sinh xuất sắc thấp, trong khi những trường được đánh giá có chất lượng trung bình (ngoại ô) có tỷ lệ học sinh xuất sắc khá cao. Đây là mâu thuần cần sớm được các cấp quản lý giáo dục xem xét, giải quyết.

Bảng 6. Khó khăn của giáo viên khi thực hiện đánh giá học sinh theo Thông tư 22

\begin{tabular}{|c|c|c|c|c|c|c|}
\hline \multirow{2}{*}{$\mathrm{Stt}$} & \multirow{2}{*}{$\begin{array}{l}\text { Khó khăn khi thực hiện các hoạt động đánh giá học sinh tiểu } \\
\text { học theo Thông tư } 22\end{array}$} & \multicolumn{5}{|c|}{ Mức độ \% } \\
\hline & & 1 & 2 & 3 & 4 & 5 \\
\hline 1 & $\begin{array}{l}\text { Có khó khăn khi phải đưa ra nhận xét bằng lời tích cực, trực } \\
\text { tiếp với từng học sinh khi đánh giá thường xuyên. }\end{array}$ & 24,1 & 8,5 & 47,8 & 16,7 & 2,7 \\
\hline 2 & $\begin{array}{l}\text { Chưa biết cách sử dụngnhững nhận xét với cảm xúc tích } \\
\text { cực, có thể "chạm đến trái tim học sinh" trong những bài } \\
\text { học/tình huống học tập. }\end{array}$ & 37,3 & 15,3 & 34,8 & 10,6 & 2,0 \\
\hline 3 & $\begin{array}{l}\text { Có khó khăn khi phải viết những lời nhận xét sao cho phù } \\
\text { hợp với từng học sinh. }\end{array}$ & 19,7 & 12,7 & 43,3 & 20,7 & 3,6 \\
\hline 4 & $\begin{array}{l}\text { Chưa quen sử dụng thang đo để đánh giá năng lực chung } \\
\text { của từng học sinh theo Thông tư } 22 \text {. }\end{array}$ & 33,5 & 16,1 & 33,1 & 14,9 & 2,3 \\
\hline 5 & $\begin{array}{l}\text { Chưa quen sử dụng thang đo để đánh giá các phẩm chất của } \\
\text { từng học sinh theo Thông tư } 22 \text {. }\end{array}$ & 35,3 & 15,0 & 33,8 & 13,0 & 2,7 \\
\hline 6 & $\begin{array}{l}\text { Khó khăn khi phải sử dụng các hiện tượng, tình huống trong } \\
\text { cuộc sông, làm thành các câu hỏi, bài tập để đánh giá năng } \\
\text { lực vận dụng của học sinh. }\end{array}$ & 21,8 & 19,2 & 44,3 & 13,3 & 1,4 \\
\hline 7 & $\begin{array}{l}\text { Hôc sinh chưa được trao nhiều cơ hội thực hành tự đánh giá } \\
\text { kêt quả học tập đề điều chỉnh hoạt động học tập. }\end{array}$ & 31,9 & 20,4 & 32,8 & 13,7 & 1,1 \\
\hline 8 & $\begin{array}{l}\text { Học sinh chưa được trao nhiều cơ hội thực hành đánh giá } \\
\text { lâ̂n nhau theo nhóm nhỏ để đồi mới hoạt động đánh giá theo } \\
\text { yêu cầu của Thông tư } 22 \text {. }\end{array}$ & 34,3 & 17,2 & 33,3 & 13,5 & 1,5 \\
\hline
\end{tabular}




\begin{tabular}{|c|c|c|c|c|c|c|}
\hline 9 & $\begin{array}{l}\text { Gặp khó khăn khi thiết kế các câu hỏi đánh giá năng lực vận } \\
\text { dụng (mức } 4 \text { - vận dụng sáng tạo/linh hoạt) trong bài kiềm } \\
\text { tra giữa kì và cuối kỳ theo Thông tư } 22 \text {. }\end{array}$ & 23,4 & 13,9 & 39,0 & 20,8 & 2,8 \\
\hline 10 & $\begin{array}{l}\text { Gặp khó khăn khi đánh giá các năng lực chung của học sinh } \\
\text { tiểu học. }\end{array}$ & 34,3 & 18,6 & 31,1 & 14,0 & 1,8 \\
\hline 11 & $\begin{array}{l}\text { Gặp khó khăn khi đánh giá các phẩm chất của học sinh } \\
\text { tiểu học. }\end{array}$ & 35,3 & 19,7 & 30,6 & 12,5 & 1,7 \\
\hline 12 & $\begin{array}{l}\text { Gặp khó khăn khi thiết kế ma trận đề và viết các câu hỏi } \\
\text { đánh giá năng lực vận dụng của học sinh (mức } 3 \text { ) theo } \\
\text { Thông tư } 22 \text {. }\end{array}$ & 25,2 & 17,8 & 36,7 & 17,3 & 2,8 \\
\hline 13 & $\begin{array}{l}\text { Gặp khó khăn khi đánh giá hiệu quả các hoạt động trải } \\
\text { nghiệm thực tế của học sinh. }\end{array}$ & 20,3 & 21,0 & 38,5 & 18,8 & 1,2 \\
\hline 14 & $\begin{array}{l}\text { Gặp khó khăn khi phải thiết kế các bài kiểm tra giữa kì, cuối } \\
\text { kì để đánh giá các năng lực chuyên biệt (ngôn ngữ, tính } \\
\text { toán, tìm hiểu Tự nhiên - Xã hội, tin học,...) của học sinh. }\end{array}$ & 26,4 & 19,1 & 34,4 & 17,1 & 2,8 \\
\hline 15 & Các khó khăn khác (ghi cụ thể): & & & & & \\
\hline
\end{tabular}

(*Mức độ: 1= Không đúng/không gặp; 2 = Hiếm khi gặp/ hiếm khi đúng;

3 = Thi thoảng gặp/đôi khi đúng; $4=$ Thường xuyên gặp/đúng; 5 = Rất thường xuyên gặp phải/rất đúng)

2.3.4. Thực trạng cách thức giáo viên thực hiện quy định đánh giá học sinh tiểu học theo Thông tư 22

Kết quả tại bảng 7 cho thấy, chỉ có $17,1 \%$ đến $18,8 \%$ giáo viên được khảo sát cho rằng các giáo viên trường họ đã thực hiện có hiệu quả các hoạt động (item số $1,2,3,5,7$ ): Tổ chức hội thảo, nghị tổng kết để giáo viên chia sẻ kinh nghiệm, khó khăn, giải pháp khi thực hiện Thông tư 22; Tổ chức các hội thảo/xemina chuyên đề về đánh giá học sinh theo Thông tư 22; Quy định đánh giá học sinh theo Thông tư 22 được trao đổi thảo luận ở các buổi sinh hoạt chuyên môn. Có $15,1 \%$ đến $17,8 \%$ giáo viên được khảo sát cho rằng các giáo viên trường họ đã thực hiện có hiệu quả các hoạt động (item số 4, 6): Giáo viên tự làm theo các văn bản liên quan đến Thông tư 22 mà trường gửi cho từng giáo viên; giáo viên tổ chức cho học sinh tự đánh giá và đánh giá lẫn nhau trong các giờ học theo yêu cầu của Thông tư 22 . Có từ $54,1 \%$ đến $64,7 \%$ giáo viên được khảo sát cho rằng các hoạt động trên đây của giáo viên trong trường đã thực hiện nhưng chưa thực sự hiệu quả. Với phát hiện này, các cấp quản lý giáo dục tiểu học cần sớm xem xét tìm cách cải thiện chất lượng các hoạt động trên.

Bảng 7. Cách thức giáo viên thực hiện đánh giá học sinh theo Thông tư 22

\begin{tabular}{|c|c|c|c|c|c|c|}
\hline \multirow{2}{*}{ Stt } & \multirow{2}{*}{$\begin{array}{l}\text { Cách thức giáo viên trong trường thực hiện đánh giá } \\
\text { học sinh theo Thông tư } 22\end{array}$} & \multicolumn{5}{|c|}{ Mức độ \% } \\
\hline & & 1 & 2 & 3 & 4 & 5 \\
\hline 1 & $\begin{array}{l}\text { Quy định đánh giá học sinh theo Thông tư } 22 \text { được trao } \\
\text { đổi thảo luận ở các buối sinh hoạt bộ môn. }\end{array}$ & 0,9 & 22,4 & 58,1 & 12,7 & 6,0 \\
\hline 2 & $\begin{array}{l}\text { Trường tổ chức các hội thảo/xemina chuyên đề cho } \\
\text { giáo viên về đánh giá học sinh theo Thông tư } 22 \text {. }\end{array}$ & 3,0 & 22,6 & 56,6 & 12,3 & 5,5 \\
\hline 3 & $\begin{array}{l}\text { Trường tổ chức tập huấn cho giáo viên về các phương } \\
\text { pháp, kỹ thuật đánh giá học sinh theo Thông tư } 22 \text {. }\end{array}$ & 0,9 & 15,6 & 64,7 & 12,2 & 6,6 \\
\hline 4 & $\begin{array}{l}\text { Giáo viên tự làm theo các văn bản liên quan đến thông } \\
\text { tư } 22 \text { mà trường gửi cho từng giáo viên. }\end{array}$ & 4,3 & 24,0 & 56,6 & 12,3 & 2,8 \\
\hline 5 & $\begin{array}{l}\text { Tổ chức hội thảo/hội nghị tồng kết để giáo viên chia sẻ } \\
\text { kinh nghiệm, khó khăn, giải pháp khi thực hiện Thông } \\
\text { tư } 22 \text {. }\end{array}$ & 4,1 & 24,5 & 54,1 & 11,8 & 5,5 \\
\hline
\end{tabular}




\begin{tabular}{|c|c|c|c|c|c|c|}
\hline 6 & $\begin{array}{l}\text { Giáo viên tổ chức cho học sinh tự đánh giá và đánh giá } \\
\text { lẫn nhau trong các giờ học theo yêu cầu của Thông } \\
\text { tư } 22 \text {. }\end{array}$ & 2,2 & 23,1 & 56,8 & 12,4 & 5,4 \\
\hline 7 & $\begin{array}{l}\text { Giáo viên được hướng dẫn thực hành cách thức thiết kế } \\
\text { ma trận đề, kĩ thuật viết cáccâu hỏi đánh giá năng lực } \\
\text { vận dụng của học sinh (mức } 3 \text { và mức } 4 \text { ) theo Thông } \\
\text { tư } 22 \text {. }\end{array}$ & 3,4 & 19,2 & 60,3 & 12,1 & 5,0 \\
\hline 8 & hoạt động khác (ghi cụ thể): & & & & & \\
\hline
\end{tabular}

(*Mức độ: 1. Chưa thực hiện; 2. Ít thực hiện 3. Đã thực hiện chưa rõ hiệu quả;

4. Thực hiện thấy rõ hiệu quả; 5 . Thực hiện cho hiệu quả tốt)

\section{Kết luận}

Quy định về đánh giá học sinh tiểu học trong Thông tư 22 là thông tư đánh giá học sinh theo hướng tiếp cận năng lực. Mặc dù đã được thực hiện hơn 2 năm, tuy nhiên, vẫn còn tồn tại nhiều khó khăn, bất cập không chỉ với cán bộ quản lí mà còn với cả đội ngũ giáo viên-những người đang trực tiếp triển khai thông tư này ở trường học $[1,5]$. Nhìn chung phần lớn giáo viên đã có những thông hiểu nhất định về mục đích, nguyên tắc, cơ sở khoa học cũng như cách thức đánh giá học sinh tiểu học. Hơn $90 \%$ giáo viên được khảo sát có những nhận định tích cực về những thay đổi ở chính bản thân cũng như ở học sinh khi thực hiện quy định đánh giá học sinh tiểu học theo Thông tư 22. Song vẫn có khoảng $41 \%$ giáo viên chưa có niềm tin tích cực về việc đánh giá, nhận xét theo tinh thần Thông tư 22; một bộ phận lớn giáo viên vẫn thích đánh giá bằng điểm số hơn vì cho rằng chỉ có đánh giá bằng điểm số mới chính xác, học sinh sẽ lười học hơn nếu đánh giá thường xuyên bằng nhận xét không kèm điểm số. Đây là những nhận thức chủ quan, cảm tính, thiếu cơ sở khoa học, nhưng một bộ phận giáo viên vẫn tin vào những nhận định này. Do vậy, rất cần thiết tiếp tục công tác tuyên truyền, tăng cường các tập huấn chuyên môn, giải thích giúp giáo viên hiểu rõ cơ sở khoa học của đánh giá thường xuyên bằng nhận xét và tầm quan trọng của những lời nhận xét trực tiếp tích cực đến khả năng phát triển học tập, nhận thức cũng như thái độ, niềm tin của học sinh. Đồng thời, cần tập huấn chuyên môn đủ sâu nhằm giúp giáo viên biết các kĩ thuật đưa ra những lời nhận xét tích cực phù hợp với các tình huống/ngữ cảnh học tập.

Trong thực hiện đánh giá học sinh theo Thông tư 22 , giáo viên cũng gặp những khó khăn nhất định: Khi viết lời nhận xét sao cho phù hợp với từng học sinh $(24,3 \%)$; khi thiết kế các câu hỏi đánh giá năng lực vận dụng $(24,3 \%), \ldots$ chỉ có từ $32,6 \%$ đến $55 \%$ giáo viên được khảo sát tự tin khẳng định mình không thực sự gặp khó khăn khi thực hiện đánh giá học sinh theo Thông tư 22.

\section{Lời cảm ơn}

Bài viết này là một phần kết quả nghiên cứu của Đề tài cấp Nhà nước: Đánh giá học sinh tiểu học theo tiếp cận năng lực đáp ứng yêu cầu đổi mới chương trình giáo dục phổ thông. Mã số đề tài: KHGD/16-20. ĐT.016.

\section{Tài liệu tham khảo}

[1] Nguyen Cong Khanh, Textbook Testing and Evaluation in education, Pedagogical University Publishing, 2017. (in Vietnamese).

[2] Ministry of Education and Training, Regulation on assessing elementary school students, Issued together with Circular No.30/2014/TT-BGDĐT August 28th, 2014. (in Vietnamese).

[3] Nguyen Cong Khanh, Assesing school students acording to the competency approach. Proceedings of international scientific seminars: "Psychology and Pedagogy in developing Vietnamese people", Educational University Publishing, 2015, pp. 688-695. (in Vietnamese). 
[4] Ministry of Education and Training, Regulation on assessing elementary school students, Issued together with Circular No.22/2016/TT-BGDĐT August 28th, 2016. (in Vietnamese).

[5] Nguyen Cong Khanh et al, Situation of implementing assessment on elementary school students under Circular 22, Thematic report, Hanoi, 2019. (in Vietnamese).
[6] Ministry of Education and Training, Report on surveying the situation of implementation of assessing elementary school students according to Circular 30, July 2016, Department of Primary Education, 2016. (in Vietnamese).

[7] Nguyen Cong Khanh, Assessment and measurement in social sciences, National Political Publishing, 2004. (in Vietnamese). 